\title{
IMPLEMENTASI QRCODE SEBAGAI TIKET MASUK EVENT DENGAN MEMPERHITUNGKAN TINGKAT KOREKSI KESALAHAN
}

\author{
Edwin Fajar Nurdiansyah ${ }^{1}$, Irawan Afrianto ${ }^{2}$ \\ ${ }^{1,2}$ Teknik Informatika - Universitas Komputer Indonesia \\ Jl. Dipatiukur 112-116 Bandung \\ E-mail : ${ }^{1}$ awingawingan@ gmail.com, ${ }^{2}$ irawan.afrianto@email.unikom.ac.id
}

\begin{abstract}
ABSTRAK
Tiket merupakan suatu dokumen yang sangat penting dalam suatu acara (event) karena tiket menentukan apakah seseorang memiliki akses untuk memasuki acara tersebut atau tidak. Untuk melakukan verifikasi tiket, petugas yang berjaga di pintu masuk harus memastikan bahwa setiap orang yang masuk dapat menunjukan tiket. Kesederhanaan sistem verifikasi tiket ini, banyak disalahgunakan untuk mendapatkan akses masuk ke dalam acara secara cuma-cuma. Tidak adanya proses identifikasi dan validasi tiket dengan data yang dimiliki oleh penyelengara acara membuat kecurangan tetap saja terjadi.

Dari permasalahan yang ada, maka dilakukan penelitian untuk memanfaatkan $\mathrm{QR}$ code sebagai tiket masuk event dengan memperhitungkan tingkat koreksi kesalahan. Penelitian ini mencoba memperbaharui sistem verifikasi tiket dengan sistem komputerisasi dengan mengganti bentuk fisik tiket menjadi QR code. Telah dilakukan pengujian alpha dan pengujian kemampuan pembacaan QR code untuk mengetahui apakah tingkat koreksi kesalahan mempengaruhi kemampuan pembacaan QR code.

Hasil dari pengujian alpha menunjukan bahwa sistem verifikasi tiket yang dibangun bebas dari kesalahan sintaks dan berjalan sesuai dengan fungsinya. Hasil dari pengujian kemampuan pembacaan QR code menyatakan bahwa tingkat koreksi kesalahan mempengaruhi kemampuan pembacaan QR code untuk QR code yang mengalami kerusakan atau bentuknya tidak utuh. Semakin tinggi tingkat koreksi kesalahan, semakin baik kemampuan pembacaan QR code.
\end{abstract}

Kata Kunci : Tiket, e-Ticketing, Sistem Verifikasi Tiket, QR code, QR scanner, Koreksi Kesalahan, Reed-Solomon.

\section{PENDAHULUAN}

Tiket merupakan suatu dokumen yang sangat penting dalam suatu acara (event) karena tiket menentukan apakah seseorang memiliki akses untuk memasuki acara tersebut atau tidak. Pada umumnya tiket berupa kertas yang memiliki ukuran sebesar uang kertas dengan cetakan gambar atau grafik khusus sesuai dengan keinginan penyelenggara acara. Untuk melakukan verifikasi tiket, petugas yang berjaga di pintu masuk harus memastikan bahwa setiap orang yang masuk dapat menunjukan tiket. Apabila tiket yang ditunjukan sesuai, petugas menyobekan sebagian dari tiket tersebut sebagai tanda bahwa tiket tersebut telah digunakan. 
Kesederhanaan sistem tiket ini, kini banyak disalahgunakan untuk mendapatkan akses masuk ke dalam acara secara cuma-cuma. Ada yang masuk dengan menggunakan potongan tiket dan berpura-pura telah masuk sebelumnya, bahkan ada yang sampai melakukan pemalsuan tiket. Seperti dilansir dalam tribunnews.com, pada pertandingan Persib melawan Persita Tanggerang ditemukan 4 buah tiket palsu dengan nomor seri yang sama. Tidak adanya proses identifikasi dan validasi tiket dengan data yang dimiliki oleh penyelengara acara membuat kecurangan tetap saja terjadi. Padahal saat ini banyak teknologi informasi yang dapat dimanfaatkan, salah satunya dengan memanfaatkan QR code sebagai tiket masuk untuk memperbaharui proses verifikasi.

Berdasarkan masalah yang telah di uraikan, Maksud dari penelitian ini adalah untuk memanfaatkan $\mathrm{QR}$ code sebagai pengganti tiket masuk event dengan memperhitungkan tingkat koreksi kesalahan.

Adapun tujuan yang ingin dicapai dari Pemanfaatan QR Code sebagai Tiket Masuk Event dengan memperhitungkan Tingkat Koreksi Kesalahan diantaranya adalah:

1. Memperbaharui proses verifikasi tiket dengan sistem komputerisasi untuk mengurangi terjadinya berbagai kecurangan pada proses verifikasi tiket.

2. Mengganti fisik tiket yang berupa kertas menjadi QR code yang dapat disematkan pada perangkat mobile.

3. Menguji kemampuan pembacaan dari $\mathrm{QR}$ code pada proses verifikasi tiket dengan tingkat koreksi kesalahan dan kondisi QR code yang berbeda-beda.

\section{ISI PENELITIAN}

\subsection{Landasan Teori}

\subsubsection{QR Code}

Quick Respons Code atau biasa disebut QR code merupakan salah satu jenis kode matriks yang pertama kali dirancang oleh industri otomotif di Jepang. Sebuah QR code menggunakan empat mode standar encoding (yaitu numerik, alfanumerik, byte / biner dan kanji) untuk menyimpan data secara efisien. Sistem QR code pun telah manjadi populer di luar industri otomotif karena pembacaan yang cepat dan kapasitas penyimpanan yang lebih besar dibandingkan dengan standar barcode UPC.

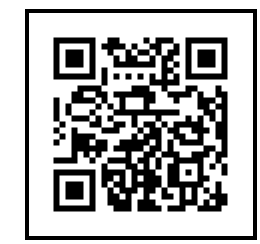

Gambar 1. Contoh QR Code

QR code terdiri dari modul hitam (titik persegi) diatur dalam kotak persegi pada latar belakang putih yang dapat dibaca oleh perangkat pencitraan seperti kamera dan diolah menggunakan koreksi kesalahan Reed-Solomon hingga gambar dapat dengan tepat di interpretasikan. Data tersebut kemudian diekstraksi dari pola yang ada dari kedua komponen horizontal dan komponen vertical pada gambar. 


\subsubsection{Storage QR Code}

Jumlah data yang dapat disimpan pada simbol QR code tergantung dari tipe data (mode, atau kumpulan karakter masukan), versi $(1, \ldots, 40$, mengindikasikan keseluruhan dimensi simbol), dan tingkat kode koreksi kesalahan. Kapasitas penyimpanan maksimum saat ini adalah untuk simbol 40-L (versi 40 dengan koreksi kesalahan tingkat low).

Tabel 1. Kapasitas Maksimum Penyimpanan

\begin{tabular}{|l|l|l|l|}
\hline $\begin{array}{l}\text { Input } \\
\text { Mode }\end{array}$ & $\begin{array}{l}\text { Maks. } \\
\text { Karakte } \\
\text { r }\end{array}$ & $\begin{array}{l}\text { Bits/ } \\
\text { Karakter }\end{array}$ & $\begin{array}{l}\text { Default } \\
\text { Encoding }\end{array}$ \\
\hline $\begin{array}{l}\text { Numeri } \\
\text { c only }\end{array}$ & 7.089 & $31 / 3$ & $\begin{array}{l}0,1,2,3, \\
4,5,6,7, \\
8,9\end{array}$ \\
\hline $\begin{array}{l}\text { Alpha- } \\
\text { numeri } \\
\text { c }\end{array}$ & 4.296 & $51 / 2$ & $\begin{array}{l}0-9, \text { A-Z Z } \\
\text { upper- } \\
\text { case } \\
\text { only), } \\
\text { space, \$, } \\
\%, ~ *,+,-, \\
., /,:\end{array}$ \\
\hline $\begin{array}{l}\text { Binary/ } \\
\text { byte }\end{array}$ & 2.953 & 8 & $\begin{array}{l}\text { ISO } \\
8859-1\end{array}$ \\
\hline $\begin{array}{l}\text { Kanji/ } \\
\text { kana }\end{array}$ & 1.817 & 13 & $\begin{array}{l}\text { Shift JIS } \\
\text { X 0208 }\end{array}$ \\
\hline
\end{tabular}

Setiap versi akan mempunyai ukuran yang berbeda dengan versi lainnya.

\subsubsection{Encoding QR Code}

Informasi format mencatat dua hal: tingkat koreksi kesalahan dan mask pattern yang digunakan untuk simbol. Masking digunakan untuk memecah pola di area data yang mungkin membingungkan scanner, seperti daerah kosong besar atau fitur menyesatkan yang terlihat seperti tanda locator. Mask pattern didefinisikan pada grid yang diulang sediperlukannya untuk menutupi seluruh simbol. Modul yang sesuai dengan daerah gelap mask terbalik. Informasi format dilindungi dari kesalahan dengan kode $\mathrm{BCH}$, dan dua salinan lengkap termasuk dalam setiap simbol QR.

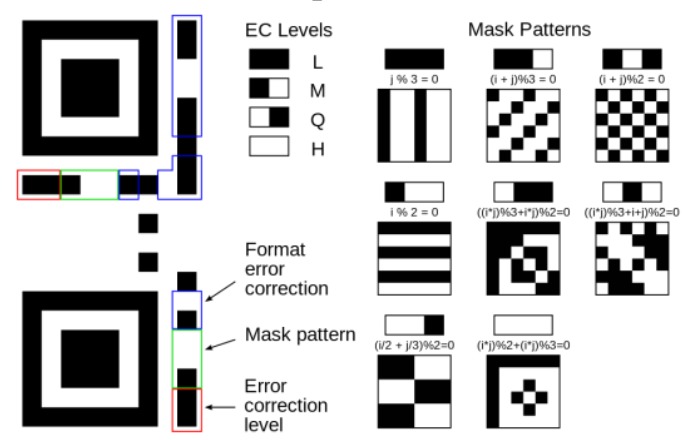

Gambar 2. Maksud Informasi Format 
Data pesan ditempatkan dari kanan ke kiri dalam pola zigzag. Dalam simbol yang lebih besar, cukup rumit karena adanya pola keselarasan dan penggunaan beberapa blok interleaved koreksi kesalahan.

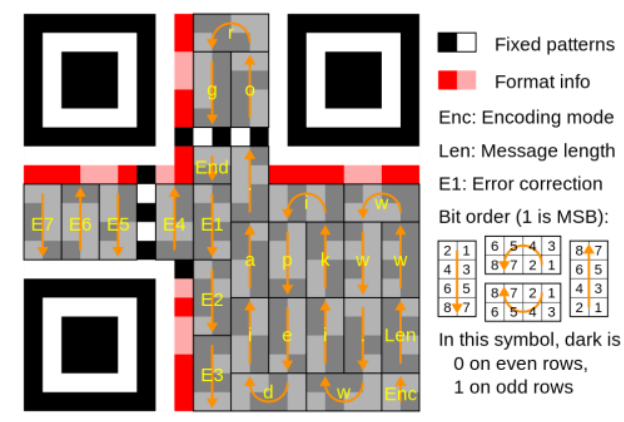

Gambar 3. Penempatan Pesan QR code

Indikator 4 bit digunakan untuk memilih mode encoding dan menyampaikan informasi lainnya. Mode pengkodean dapat dicampur sesuai kebutuhan dalam simbol QR.

Tabel 2. Menu Encoding

\begin{tabular}{|l|l|}
\hline Indikator & Keterangan \\
\hline 0001 & $\begin{array}{l}\text { Numeric encoding (10 bits per 3 } \\
\text { digits) }\end{array}$ \\
\hline 0010 & $\begin{array}{l}\text { Alphanumeric encoding (11 bits per } \\
\text { 2 characters) }\end{array}$ \\
\hline 0100 & Byte encoding (8 bits per character) \\
\hline 1000 & $\begin{array}{l}\text { Kanji encoding (13 bits per } \\
\text { character) }\end{array}$ \\
\hline 0011 & $\begin{array}{l}\text { Structured append (used to split a } \\
\text { message across multiple QR } \\
\text { symbols) }\end{array}$ \\
\hline 0101 & $\begin{array}{l}\text { Extended Channel Interpretation } \\
\text { (select alternate character set or } \\
\text { encoding) }\end{array}$ \\
\hline $\begin{array}{l}\text { FNC1 in first position (see Code 128 } \\
\text { for more information) }\end{array}$ \\
\hline 001 & FNC1 in second position \\
\hline 0000 & End of message \\
\hline
\end{tabular}

Setelah setiap indikator memilih mode encoding, panjang field lah yang memberitahu berapa banyak karakter dikodekan dalam mode tersebut. Jumlah bit pada panjang field tergantung pada encoding dan versi simbol.

Tabel 3. Jumlah Bit Per Panjang Field

\begin{tabular}{|l|l|l|l|}
\hline Encoding & Ver.1-9 & $\mathbf{1 0 - 2 6}$ & $\mathbf{2 7 - 4 0}$ \\
\hline Numerik & 10 & 12 & 14 \\
\hline Alfanumerik & 9 & 11 & 13 \\
\hline Byte & 8 & 16 & 16 \\
\hline Kanji & 8 & 10 & 12 \\
\hline
\end{tabular}


Mode encoding alfanumerik menyimpan pesan lebih kompak daripada yang mode byte, tetetapi mode alfanumerik tidak bisa menyimpan huruf-huruf non-kapital dan memiliki pilihan tanda baca terbatas yang cukup untuk alamat web yang belum sempurna. Dua karakter dikodekan dalam nilai 11-bit dengan rumus:

$V=45 \times C_{1}+C_{2}$

Tabel 4. Kode Karakter Alfanumerik

\begin{tabular}{|l|c|l|c|}
\hline Kode & Karakter & Kode & Karakter \\
\hline 00 & 0 & 23 & N \\
\hline 01 & 1 & 24 & O \\
\hline 02 & 2 & 25 & P \\
\hline 03 & 3 & 26 & Q \\
\hline 04 & 4 & 27 & R \\
\hline 05 & 5 & 28 & S \\
\hline 06 & 6 & 29 & T \\
\hline 07 & 7 & 30 & U \\
\hline 08 & 8 & 31 & V \\
\hline 09 & 9 & 32 & W \\
\hline 10 & A & 33 & X \\
\hline 11 & B & 34 & Y \\
\hline 12 & C & 35 & Z \\
\hline 13 & D & 36 & SP \\
\hline 14 & E & 37 & $\$$ \\
\hline 15 & F & 38 & $\%$ \\
\hline 16 & G & 39 & $*$ \\
\hline 17 & H & 40 & + \\
\hline 18 & I & 41 & - \\
\hline 19 & J & 42 &. \\
\hline 20 & K & 43 & / \\
\hline 21 & L & 44 & $:$ \\
\hline 22 & M & & \\
\hline
\end{tabular}

\subsubsection{Koreksi Kesalahan}

Codeword dengan panjang 8 bit dan menggunakan algoritma koreksi kesalahan Reed-Solomon dengan empat tingkat koreksi kesalahan. Semakin tinggi tingkat koreksi kesalahan, kapasitas penyimpanan akan semakin kurang.

Tabel 5. Tabel Tingkat Koreksi Kesalahan

\begin{tabular}{|l|l|c|}
\hline $\begin{array}{l}\text { Tingkat } \\
\text { EC }\end{array}$ & $\begin{array}{l}\text { Kemampuan } \\
\text { Koreksi Kesalahan }\end{array}$ & Indikator \\
\hline $\begin{array}{l}\text { Level L } \\
\text { (Low) }\end{array}$ & $\begin{array}{l}\text { 7\% dari codewords } \\
\text { dapat dikembalikan }\end{array}$ & 01 \\
\hline $\begin{array}{l}\text { Level M } \\
\text { (Medium) }\end{array}$ & $\begin{array}{l}15 \% \text { dari } \\
\text { codewords dapat } \\
\text { dikembalikan }\end{array}$ & 00 \\
\hline Level Q & $25 \%$ dari & 11 \\
\hline
\end{tabular}




\begin{tabular}{|l|l|c|}
\hline (Quartile) & $\begin{array}{l}\text { codewords dapat } \\
\text { dikembalikan }\end{array}$ & \\
\hline $\begin{array}{l}\text { Level H } \\
\text { (High) }\end{array}$ & $\begin{array}{l}30 \% \text { dari } \\
\text { codewords dapat } \\
\text { dikembalikan }\end{array}$ & 10 \\
\hline
\end{tabular}

Dalam simbol QR code yang lebih besar, pesan akan dipecah menjadi beberapa blok kode Reed-Solomon. Ukuran dipilih sehingga paling banyak 15 kesalahan dapat diperbaiki di setiap blok, ini membatasi kompleksitas dari algoritma decoding. Blok kode tersebut kemudian disisipkan bersama-sama, sehingga lebih kecil kemungkinannya bahwa kerusakan lokal untuk simbol QR akan membanjiri kapasitas setiap blok tunggal. Tingkat Koreksi kesalahan (EC Level) dan versi dari QR code ini dapat menentukan jumlah data yang dapat ditampung dalam setiap QR code.

\subsubsection{Decoding QR Code}

Decoding adalah proses pembacaaan QR code untuk menghasilkan informasi dari data yang ada pada QR code. Decoding merupakan kebalikan dari proses encoding yang merupakan proses untuk mengubah data ke dalam bentuk QR code. Ada beberapa bagian pada QR code yang dapat dilihat secara manual seperti pada Gambar 4.

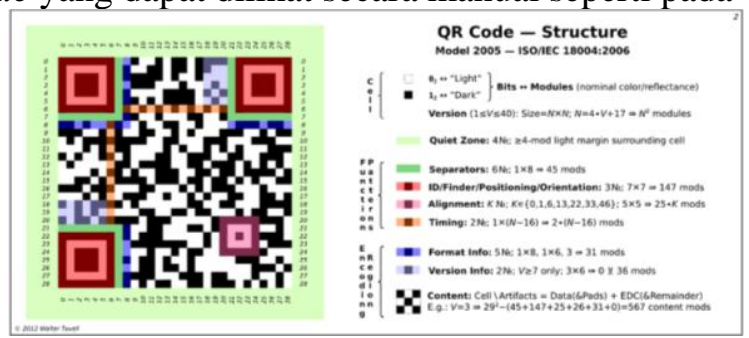

Gambar 4. Lokasi Area QR Code

\subsubsection{Reed-Solomon Error Correction Code}

Reed-Solomon code adalah kode siklik nonbiner yang terbuat dari $2 \mathrm{n}$ bit biner dimana $m$ lebih besar daripada 2. Diciptakan oleh Irving S. Reed dan Gustave Solomon. Mereka menjelaskan secara sistematis kode bangunan yang dapat mendeteksi dan memperbaiki beberapa kesalahan simbol acak. Untuk sebuah codeword, panjang kode adalah 8 bit, maka Reed-Solomon code: $28-1=255$. Untuk mengkoreksi kesalahan pada codeword, maka ditambahkan Reed-Solomon code agar dapat terlindung dari kerusakan tanpa harus kehilangan data. Kemampuan koreksi error-nya bergantung pada jumlah data yang dikodekan. Reed-Solomon code terdiri atas 2 bagian, yaitu bagian data dan bagian paritas. Reed-Solomon code dinyatakan dengan kode $(\mathrm{n}, \mathrm{k})$ atau $\mathrm{RS}(\mathrm{n}, \mathrm{k})$ dimana $\mathrm{n}$ adalah maksimum codeword, yaitu 255, sedangkan $\mathrm{k}$ adalah jumlah dari codeword data. Berikut ini merupakan penjelasan dari gambar 5 mengenai struktur Reed-Solomon code.

\begin{tabular}{|l|c|}
\hline$k$ \\
\hline DATA & $2 f$ \\
\hline
\end{tabular}

Gambar 5. Struktur Reed-Solomon Code 
2t atau simbol paritas adalah codeword yang digunakan untuk koreksi kesalahan dengan nilai maksimun adalah t. Sebagai contoh, RS $(255,223)$ artinya terdapat total 255 codeword yang terdiri atas 223 codeword data dan 32 codeword paritas.

$$
\begin{aligned}
& \mathrm{n}=255, \mathrm{k}=223 \\
& 2 \mathrm{t}=(255-223) \rightarrow \mathrm{t}=16
\end{aligned}
$$

sehingga kesalahan yang dapat diperbaiki adalah sebanyak 16 codeword. Sebagai informasi 1 codeword adalah 8 bit, sehingga total koreksi yang dapat diperbaiki adalah $16 \times 8$ bit $=128$ bit.

Ketika panjang Reed-Solomon code kurang dari 28 - 1, maka padding 0 digunakan untuk membuat Reed-Solomon code tepat $28-1$. Sewaktu proses pembacaan kode, padding 0 akan dibuang. Hal ini disebut dengan penyingkatan Reed-Solomon code. Sebagai contoh, misalkan terdapat 100 codeword data untuk mengkoreksi 8 buah kesalahan, sehingga akan dibutuhkan tambahan 16 codeword paritas. Jadi total keseluruhan dari codeword menjadi 116, yang mana masih kurang dari $28-1$, sehingga harus ditambahkan 139 codeword padding 0 .

\subsection{Analisis Sistem}

Untuk mengganti fisik sebuah tiket menjadi QR code, diperlukan aplikasi yang terdiri dari server yang juga berfungsi sebagai encoder dan scanner yang berfungsi juga sebagai decoder. Pada penelitian ini, encoder dibangun pada flatform website karena tiket yang dikelola merupakan tiket yang dijual secara presale (dijual pada hari-hari sebelum dilaksanakannya event) sehingga membutuhkan sebuah website untuk melakukan penjualan secara online. Penjualan tiket dilakukan secara online untuk menghindari antrian yang berlebihan.

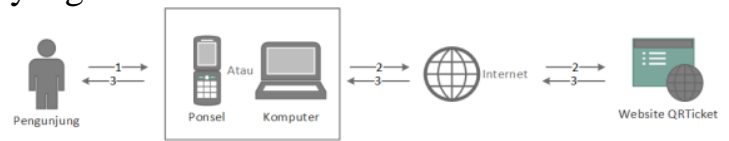

Gambar 6. Gambaran Umum Proses Pemesanan Tiket

Keterangan:

1) Pengunjung mengakses website/server menggunakan ponsel atau pun komputer melalui internet dan melakukan pemesanan tiket dengan mengisi form pemesanan dengan data yang valid.

2) Data pemesanan tiket dikirim ke server melalui internet.

3) Server akan memberikan kode registrasi untuk digunakan ketika mengirimkan nomor resi pembayaran.

Karena penelitian ini tidak membahas pembayaran tiket, maka diasumsikan pembayaran dilakukan dengan cara sebagai berikut.

1) Pengunjung melakukan transfer ke rekening penyelenggara acara.

2) Pengunjung mengakses website dan menginputkan nomor registrasi pada Form Pembayaran sebagai autentifikasi pengunjung.

3) Jika nomor registrasi valid, pengunjung mengirimkan bukti transfer atau nomor resi pembayaran melalui Form Pembayaran.

4) Setelah pengunjung mengirimkan nomor resi pembayaran, sistem akan melakukan encoding QR code dengan status "Non-aktif" dan pengunjung pun dapat mengunduh tiket dalam bentuk QR code.

5) Administrator melakukan verifikasi secara manual untuk menentukan validitas dari bukti transfer yang dikirimkan pengunjung. Apabila valid, maka administrator akan 
melakukan update pada status pembayaran menjadi lunas, sehingga status tiket pun akan ikut terupdate menjadi "Aktif".

Perlu diketahui, tiket QR code yang ada pada sistem ini memiliki tiga jenis status yang berbeda. Hanya tiket yang berstatus "Aktif" yang dianggap valid oleh sistem ketika proses verifikasi tiket.

Tabel 6. Keterangan Status Tiket

\begin{tabular}{|l|l|lr|}
\hline No & Status Tiket & Keterangan \\
\hline 1 & Non-Aktif & $\begin{array}{l}\text { Ketika pertama kali } \\
\text { dibangkitkan } \\
\text { user telah mengirimkan } \\
\text { nomor resi pembayaran) }\end{array}$ \\
\hline 2 & Aktif & $\begin{array}{l}\text { Ketika administrator } \\
\text { mengubah status } \\
\text { pembayaran menjadi } \\
\text { lunas (nomor resi } \\
\text { pembayaran terbukti } \\
\text { valid) }\end{array}$ \\
\hline 3 & Terverifikasi & $\begin{array}{l}\text { Ketika petugas pemeriksa } \\
\text { tiket melakukan verifikasi } \\
\text { terhadap tiket dengan } \\
\text { status "Aktif". Tiket } \\
\text { dengan status } \\
\text { "Terverifikasi" } \\
\text { menandakan bahwa tiket } \\
\text { tersebut telah digunakan } \\
\text { sehingga dalam sistem } \\
\text { tiket tersebut tidaklah } \\
\text { valid }\end{array}$ \\
\hline
\end{tabular}

Selain proses encoding QR code dan pemesanan tiket, website ini juga berfungsi sebagai server yang menyimpan dan mengelola data acara, data pemesanan dan data tiket. Fungsional pada pengelolaan data ini berupa tambah, edit dan hapus data. Data pemesanan yang dikelola adalah status pembayaran dimana status pembayaran ini juga mempengaruhi status dari tiket yang dibeli. Seluruh pengelolaan ini dikelola oleh administrator.

Decoder pada sistem ini berupa aplikasi scanner yang dibangun pada platform Android. Nantinya, aplikasi scanner ini harus terinstal pada telepon seluler bersistem operasi Android yang memiliki kamera serta dapat terhubung dengan jaringan internet. Hal ini diperlukan untuk melakukan proses verifikasi secara langsung dan mencocokan data tiket dari data hasil decoding $\mathrm{QR}$ code dengan data tiket pada server.

Sebelum melakukan verifiaksi tiket, petugas pemeriksa tiket harus memilih event terlebih dahulu sesuai dengan event yang berlangsung dengan memasukan kode event yang petugas dapatkan dari administrator atau koordinator acara. Apabila tiket yang dimiliki pengunjung sesuai dengan event tersebut dan memiliki status "Aktif", maka proses verifikasi tiket ini akan menggati status tiket menjadi "Terverifikasi”. 


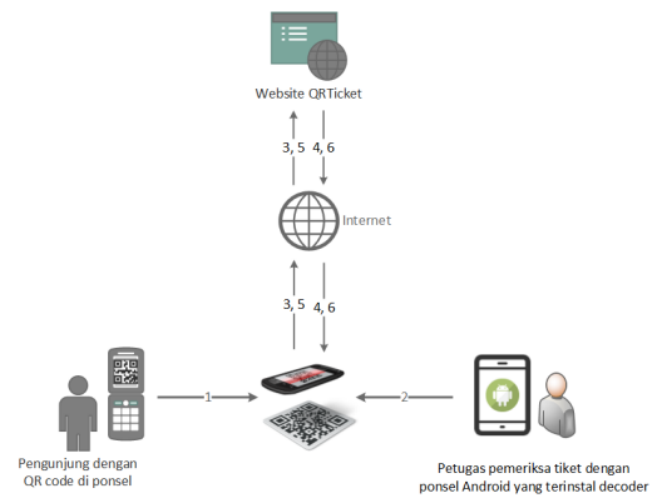

Gambar 7. Gambaran Umum Proses Verifikasi Tiket

Keterangan:

1) Pengunjung memperlihatkan tiket $\mathrm{QR}$ code yang ada pada ponselnya kepada petugas penjaga pintu masuk.

2) Petugas memilih event sesuai dengan event yang berlangsung saat itu. Kemudian petugas melukakan verifikasi tiket menggunakan aplikasi decoder yang terinstal pada perangkat Androidnya.

3) Jika data pada QR code terbaca, decoder akan mengirimkan data dari hasil decoding tersebut melalui internet. Kemudian server melakukan verifikasi terhadap data tersebut.

4) Server mengirimkan hasil validasi dari nomor tiket tersebut ke decoder. Apabila tiket valid (nomor tiket terdaftar, nomor event sesuai dengan event yang berlangsung dan status tiket “Aktif”) maka tiket dapat diproses.

5) Petugas pemeriksa tiket menekan tombol verifikasi. Verifiaksi disini, ialah mengganti status tiket menjadi "Terverifikasi". Decoder akan meminta server untuk mengganti status tiket yang "Aktif" tersebut menjadi "Terverifikasi" sebagai tanda bahwa tiket telah digunakan.

6) Jika update berhasil, server akan mengirimkan pesan ke decoder bahwa tiket telah terverifikasi.

\subsubsection{Analisis Encoding QR Code}

Encoding QR code merupakan proses mengkodekan data pada QR code. Pada penelitian ini, data yang dikodekan berupa nomor tiket. Misalkan ambil contoh nomor tiket adalah "BMT00384" yang terdiri dari 8 digit dan QR code yang digunakan adalah versi 1 dengan koreksi kesalahan tingkat High (1-H) dimana 30\% dari jumlah codewords data dapat dikembalikan. Ini semua berkat adanya kode koreksi kesalahan Reed-Solomon.

Pada proses encoding QR code, data yang akan dikodekan akan dibentuk menjadi codewords data. Kemudian kode koreksi kesalahan Reed-Solomon akan membentuk suatu codewords baru. Codewords ini akan menyimpan data yang sama dengan data yang ada pada codewords data yang berfungsi sebagai cadangan apabila data pada codewords data tidak terbaca oleh pemindai. 


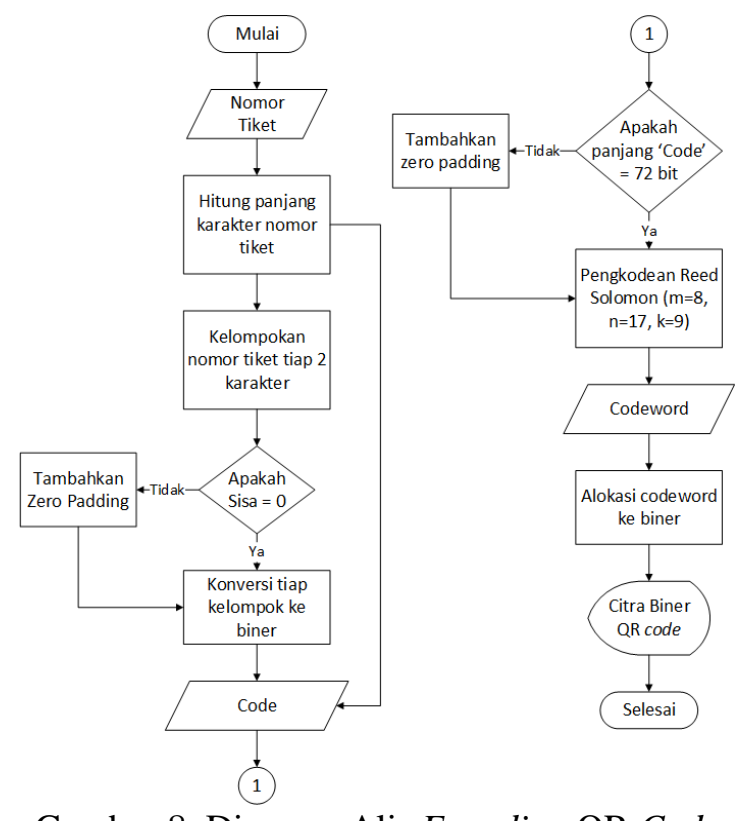

Gambar 8. Diagram Alir Encoding QR Code

Langkah-langkah yang dilakukan saat proses encoding data menjadi codewords dapat juga dituliskan dengan singkat sebagai berikut.

1) Perhitungan jumlah karakter serta pemberian indikator mode.

2) Encoding data dalam representasi biner.

3) Pemenuhan jumlah bit dan simbol sesuai dengan jumlah yang ditentukan

4) Menghitung codeword kode koreksi kesalahan Reed-Solomon.

\subsubsection{Perhitungan Jumlah Karakter}

Indikator mode dibuat dengan panjang 4 bit sebagai representasi biner seperti pada Tabel 2. Data yang dikodekan adalah "BMT00384", itu berarti data yang digunakan adalah alfanumerik. Maka indikator mode yang dipilih sesuai adalah 0010.

Indikator jumlah karakter adalah jumlah karakter yang dapat disimpan dalam setiap mode. Seperti pada Tabel 3 untuk data alfanumerik, panjang representasi binernya adalah 9 bit. Panjang contoh nomor tiket adalah 8 bit, maka 8 bit direpresentasikan dalam biner adalah 000001000 sehingga bilangan biner yang sudah terbentuk adalah 0010000001000.

\subsubsection{Encoding Data dalam Representasi Biner}

Dalam mode alfanumerik, setiap karakter di konversikan ke dalam nilai sesuai dengan Tabel 4. Data dibagi dalam kelompok-kelompok per 2 karakter dimana nilai dari karakter pertama dikali 45 hasilnya ditambah dengan nilai karakter kedua. Seperti dijelaskan pada rumus (1). Kemudian nilai dari V dikodekan dalam representasi biner sepanjang 11 bit. Tabel 7 merupakan hasil penguraian dari nomor tiket "BMT00384".

Tabel 7. Encoding Data dalam Representasi Biner

\begin{tabular}{|l|l|l|l|}
\hline "BM" & "T0" & "03" & "84" \\
\hline $45 * 11+22$ & $45 * 29+0$ & $45^{*} 0+3$ & $45 * 8+4$ \\
\hline
\end{tabular}




\begin{tabular}{|l|l|l|l|}
\hline 517 & 553 & 3 & 93 \\
\hline 01000000101 & 10100011001 & 00000000011 & 00101101100 \\
\hline
\end{tabular}

Lalu lakukan terminator atau penambahkan biner 0000 kepada hasil representasi biner. Akan tetapi jika panjang data yang di encode penuh sesuai dengan versi dan tingkat koreksi kesalahan, maka tidak perlu dilakukan terminator sehingga didapat deret bit 0010000001000010000001011010001100100000000011001011011000000 .

\subsubsection{Pemenuhan Jumlah Bit dan Simbol}

Hasil representasi data nomor tiket 00100000010000100000010110100011001 00000000011001011011000000 kemudian dikelompokan setiap 8bit. Sehingga hasil representasi tersebut menjadi:

0010000001000010000001011010001100100000000011001011011000000

Jika terdapat kelompok dengan panjang data kurang dari 8 bit, maka tambahkan 0 sampai menjadi 8 bit. Penambahan " 0 " inilah yang dinamakan zero padding. Penambahan zero padding tersebut diperlukan karena jumlah simbol yang menjadi masukan Reed-Solomon harus tetap yaitu 8 bit disebut dengan codeowrds. Setelah dilakukan zero padding, maka kelompok atau deret codewords tersebut menjadi:

0010000001000010000001011010001100100000000011001011011000000000

Jika jumlah codewords kurang dari kapasitas simbol, maka tambahkan byte "11101100" dan "00010001" secara bergantian hingga panjang bit memenuhi kapasitas maksimum yang telah ditentukan. Byte tersebut masing-masing ekuivalen dengan 236 dan 17. Kedua byte tersebut secara khusus diperlukan oleh spesifikasi QR code untuk ditambahkan jika bit string terlalu pendek pada tahap ini.

Untuk kapasitas maksimum QR code versi 1 dengan tingkat koreksi kesalahan High, didapat bahwa QR code 1-H memiliki kapasitas maksimum 9 codewords. Jika dikalikan dengan 8 bit maka representasi biner tersebut harus berjumlah 72 bit.
1: 00100000
5: 00100000
2: 01000010
6: 00001100
3: 00000101
7: 10110110
4: 10100011
8: 0000000

Setelah dihitung, jumlah codewords pada representasi biner berjumlah 8 codewords dengan jumlah bit sebesar 64 bit sehingga perlu dilakukan penambahan byte "11101100". Maka kapasitas dari representasi biner tersebut telah berjumlah 9 codewords.
1: 00100000
6: 00001100
2: 01000010
7: 10110110
3: 00000101
8: 0000000
4: 10100011
9: 11101100
5: 00100000

Kemudian codewords tersebut dikonversi kembali kedalam bilangan desimal sehingga diperoleh deret desimal 3266516332121820 236. Deret desimal tersebut nantinya akan menjadi masukan dalam proses pengkodean Reed-Solomon.

\subsubsection{Menghitung Codewords Kode Koreksi Kesalahan}

Pertama hasil encoding data yaitu 3266516332121820236 dipisah sesuai ketentuan dari blok RS pada. Kemudian pilih rumus $\mathrm{g}(\mathrm{x})$ berdasarkan jumlah Error- 
Correction codewords per blok dari sesuai dengan versi QR code dan tingkat koreksi kesalahan.

1) Langkah Divisi Polinomial

Langkah pertama untuk divisi ini adalah mempersiapkan polinomial pesan untuk divisi. Polinom pesan lengkap adalah:

$32 \times 8+66 \times 7+5 \times 6+163 \times 5+32 \times 4+12 \times 3+182 \times 2+0 \times 1+23$

Untuk memastikan bahwa eksponen dari variabel pertama tidak menjadi terlalu kecil selama divisi, kalikan polinomial pesan dengan xn dimana $\mathrm{n}$ adalah jumlah codewords koreksi kesalahan yang diperlukan. Dalam hal ini n adalah 17, untuk 17 codewords koreksi kesalahan, kalikan polinomial pesan oleh x17, maka akan mendapatkan hasil:

$32 \times 25+66 \times 24+5 \times 23+163 \times 22+32 \times 21+12 \times 20+182 \times 19+0 \times 18+236 \times 17$ ...(3)

Istilah utama dari generator polinomial juga harus memiliki eksponen yang sama, jadi kalikan dengan $x 8$ untuk mendapatkan

$\alpha 0 \times 25+\alpha 43 \times 24+\alpha 139 \times 23 \alpha 206 \times 22+\alpha 78 \times 21 \alpha 43 \times 20+\alpha 239 \times 19+\alpha 123 \times 18+$ $\alpha 206 \times 17+\alpha 214 \times 16+\alpha 147 \times 15 \alpha 24 \times 14+\alpha 99 \times 13 \alpha 150 \times 12+\alpha 39 \times 11 \alpha 243 \times 10+$ $\alpha 163 \times 9+\alpha 136 \times 8$

Sekarang sudah mungkin untuk melakukan langkah-langkah pembagian berulang. Jumlah langkah di divisi harus sama dengan jumlah variabel dalam polinomial pesan. Dalam hal ini, divisi ini akan mengambil 9 langkah untuk menyelesaikan. Hal ini akan menghasilkan sisa yang memiliki 17 variabel. Istilah-istilah ini akan menjadi 17 codewords koreksi kesalahan yang diperlukan.

2) Langkah 1a: Kalikan Generator Polinomial dengan Variabel Pertama pada Polinomial Pesan

Langkah pertama adalah untuk memperbanyak generator polinomial dengan variabel pertama dari polinomial pesan. Dalam studi kasus ini, variabel pertama adalah $32 \times 25$. Karena notasi a membuatnya lebih mudah untuk melakukan perkalian, dianjurkan untuk mengkonversi 32x25 notasi $\alpha$. Untuk nilai integer 32, eksponen $\alpha$ adalah 5 . Oleh karena $32=\alpha 5$. Kalikan generator polinomial oleh $\alpha 5$ :

$(\alpha 5 * \alpha 0) \times 25+\left(\alpha 5^{*} \alpha 43\right) \times 24+(\alpha 5 * \alpha 139) \times 23+(\alpha 5 * \alpha 206) \times 22+(\alpha 5 * \alpha 78)$ $\mathrm{x} 21+(\alpha 5 * \alpha 43) \times 20+(\alpha 5 * \alpha 239) \times 19+(\alpha 5 * \alpha 123) \times 18+(\alpha 5 * \alpha 206) \times 17+(\alpha 5 *$ $\alpha 214) \times 16+(\alpha 5 * \alpha 147) \times 15+(\alpha 5 * \alpha 24) \times 14+(\alpha 5 * \alpha 99) \times 13+(\alpha 5 * \alpha 150) \times 12+$ $(\alpha 5 * \alpha 39) \times 11+(\alpha 5 * \alpha 243) \times 10+(\alpha 5 * \alpha 163) \times 9+(\alpha 5 * \alpha 136) \times 8$

Eksponen dari $\alpha$ ditambahkan bersama-sama. Hasilnya adalah:

$\alpha 5 \times 25+\alpha 48 \times 24+\alpha 144 \times 23+\alpha 211 \times 22+\alpha 83 \times 21+\alpha 48 \times 20+\alpha 244 \times 19+\alpha 128 \times 18+$ $\alpha 211 \times 17+\alpha 219 \times 16+\alpha 152 \times 15+\alpha 29 \times 14+\alpha 104 \times 13+\alpha 155 \times 12+\alpha 44 \times 11 \alpha 248 \times 10+$ $\alpha 168 \times 9+\alpha 141 \times 8 \ldots(6)$

Sekarang, konversikan kembali ke notasi integer:

$32 \times 25+70 \times 24+168 \times 23+178 \times 22+187 \times 21+70 \times 20+250 \times 19+133 \times 18+178 \times 17$ $+86 \times 16+73 \times 15+48 \times 14+13 \times 13+114 \times 12+238 \times 11+27 \times 10+252 \times 9+21 \times 8 \ldots$.(7)

3) Langkah 1b: XOR hasil dengan polinomial pesan

Karena ini adalah langkah divisi pertama, lakukan operasi XOR hasil dari 1a dengan polinomial pesan.

$(32 \oplus 32) \times 25+(66 \bigoplus 70) \times 24+(5 \oplus 168) \times 23+(163 \oplus 178) \times 22+(32 \oplus 187)$ $\mathrm{x} 21+(12 \bigoplus 70) \times 20+(182 \bigoplus 250) \times 19+(0 \bigoplus 133) \times 18+(236 \bigoplus 178) \times 17+(0 \oplus$ 86) $\times 16+(0 \oplus 73) \times 15+(0 \bigoplus 48) \times 14+(0 \oplus 13) \times 13+(0 \bigoplus 114) \times 12+(0 \oplus 238)$ $\mathrm{x} 11+(0 \oplus 27) \mathrm{x} 10+(0 \oplus 252) \mathrm{x} 9+(0 \oplus 21) \mathrm{x} 8$ 
Hasilnya adalah :

$0 \times 25+4 \times 24+17 \times 22+173 \times 23+155 \times 21+74 \times 20+76 \times 19+133 \times 18+94 \times 17+$ $86 \times 16+73 \times 15+48 \times 14+13 \times 13+114 \times 12+238 \times 11+27 \times 10+252 \times 9+21 \times 8$

Buang variabel depan 0 untuk mendapatkan:

$4 \times 24+17 \times 22+173 \times 23+155 \times 21+74 \times 20+76 \times 19+133 \times 18+94 \times 17+86 \times 16+$ $73 \times 15+48 \times 14+13 \times 13+114 \times 12+238 \times 11+27 \times 10+252 \times 9+21 \times 8$

4) Langkah 2 Lakukan Iterasi Hingga Akhir

Setelah mendapatkan hasil XOR pada langkah 1b, lakukan kembali iterasi seperti pada langkah 1a dan 1b hingga mendapatkan hasil:

$76 \times 16+27 \times 15+190 \times 14+249 \times 13+106 \times 12+237 \times 11+203 \times 10+70 \times 9+90 \times 8+$ $167 \times 7+150 \times 6+71 \times 5+99 \times 4+75 \times 3+32 \times 2+230 \times 1+106$

5) Menggunakan variabel sisanya sebagai codewords koreksi kesalahan

Divisi ini telah dilakukan 9 kali, yang merupakan jumlah variabel dalam polinomial pesan. Ini berarti bahwa iterasi selesai dan ketentuan polinomial di atas adalah codewords koreksi kesalahan yang digunakan untuk pesan polinomial asli:

7627190249106237203709016715071997532230106

Seluruh proses menghitung codewors koreksi kesalahan dapat juga dilihat dalam bentuk diagram alir.
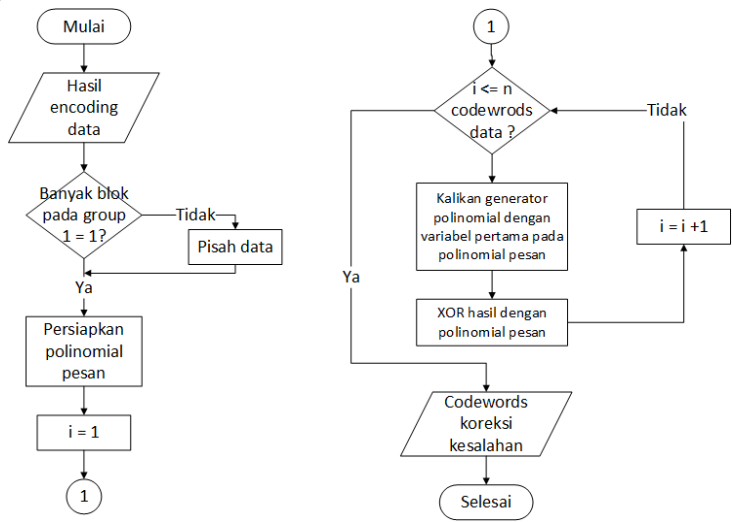

Gambar 9. Diagram Alir Menghitung Codewords Koreksi Kesalahan

\subsubsection{Alokasi Codewords ke Biner}

Pada QR code, 1 modul berarti 1 bit. Data hasil di bagian sebelumnya dikodekan ke representasi biner, kemudian data tersebut dialokasikan. Selain itu, ketika nomor blok RS adalah 2 atau lebih tinggi, maka data harus dialokasikan dalam interleaved. Dalam contoh data, untuk 1-H (QR code versi 1 dengan tingkat koreksi kesalahan $\mathrm{H}$ ) memiliki 1 RS blok, data tidak perlu dialokasikan dalam interleave. Ada beberapa aturan untuk alokasi data, diantaranya:

1) Pengalokasian memiliki koordinat, i menunjukan baris dan j menunjukan kolom. Pojok kiri atas, memiliki koordinat $(0,0)$. Untuk QR code versi 1 ini, memiliki modul dari $(0,0)$ hingga $(20,20)$.

2) Awal modul adalah pojok kanan bawah. Pada QR code $1-\mathrm{H}$ ini, awal modul adalah $(20,20)$.

3) Setiap codewords terdiri dari 8 bit, sehingga pengalokasian pun dikelompokan menjadi 8 modul dengan ukuran modul $2 \times 4$. 
4) Pola pengalokasian data dimulai dari bawah keatas kemudian dari atas kebawah, terus berlanjut hingga akhir.

5) Ketika alokasi data sedang mengarah keatas, maka data pun akan dialokasikan secara zig-zag ke arah atas. Mulai dari $(20,20)$, kemudian berlanjut ke $(19,20)$, $(19,19),(20,19)$ hingga $(20,17)$ kemudian dilanjutkan ke codeword berikutnya.

6) Ketika alokasi data sedang mengarah kebawah, maka data pun akan dialokasikan ke arah bawah, tetap dengan pola zig-zag.

Setelah didapatkan desimal codewords data dan codewords koreksi kesalahan dari bagian sebelumnya maka tambahkan codewords koreksi kesalahan ke codewords data sehingga didapatkan:

32665163321218202367627190249106237203709016715071997532 230106

Kemudian konversikan kembali codewords ke biner dan lakukan operasi XOR. Kemudian deretan bit-bit codewords data tersebut dialokasikan seperti yang telah dijelaskan sebelumnya untuk mengisi modul-modul yang ada pada QR code. Posisi codewords koreksi kesalahan akan berada tepat setelah codewords data.

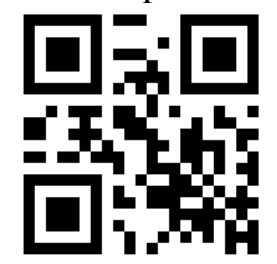

Gambar 10. QR Code Hasil Encoding Data "BMT00384"

\subsubsection{Analisis Decoding QR Code}

Sistem decoder yang dibangun berbasis mobile untuk mempermudah mobilitas pemeriksa tiket dalam memeriksa tiketnya. Decoder ini akan memanfaatkan kamera yang ada pada perangkat mobile untuk menangkap QR code. Kemudian QR code tersebut akan di decode untuk mengetahui isi data nomor tiket yang ada pada $\mathrm{QR}$ code.

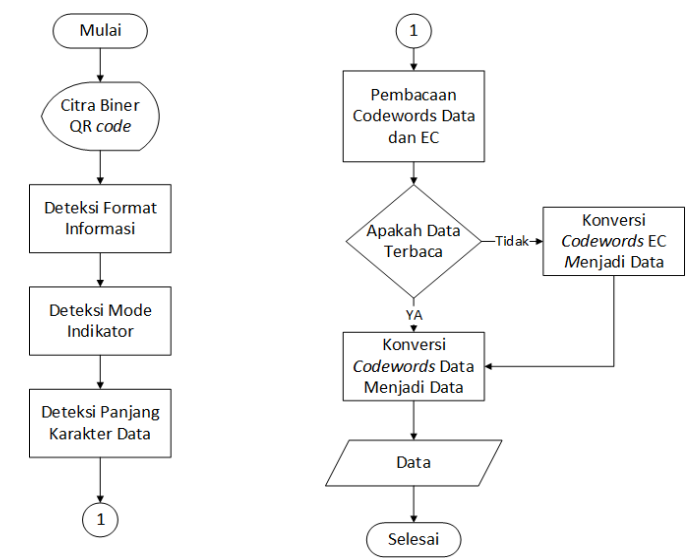

Gambar 11. Diagram Alir Decoding QR Code

Proses decoding akan memanfaatkan library dari ZXing sehingga decoder akan melakukan pemanggilan class yang telah disertakan dari ZXing. Apabila QR code berhasil di decode maka, decoder akan menampilkan data hasil decoding tersebut dan 
kemudian mengirimkan data tersebut ke server untuk kemudian dilakukan verifikasi tiket.

Langkah-langkah yang dilakukan pada proses decoding QR code menjadi data dapat juga dituliskan dengan singkat sebgai berikut.

1) Deteksi format informasi, mode indikator dan panjang karakter data.

2) Pembacaan isi pada $\mathrm{QR}$ code yang berupa codewords.

3) Konversi kembali codewords data menjadi data.

\subsubsection{Pembacaan Tiket}

Sebelum melakukan validasi tiket, petugas pemeriksa tiket harus memasukan kode event terlebih dahulu untuk memastikan bahwa tiket yang diverifikasi merupakan tiket event yang bersesuai dengan event yang berlangsung.

Setelah event yang dipilih valid, maka dilakukan decoding pada tiket QR code tersebut. Setelah itu, didapatkan hasil decoding yang berupa data yang seharusnya adalah nomor tiket. Kemudian data tersebut dikirimkan ke server melaui internet. Setelah itu server akan mencocokan kode event, nomor tiket dan status tiket dengan data yang ada pada database. Hanya tiket yang memiliki status Aktif lah yang dinyatakan valid oleh sistem.

Setelah server melakukan validasi dengan database, maka server akan mengirimkan hasil validasi tersebut. Jika data tersebut merupakan nomor tiket yang valid, maka petugas pemeriksa tiket dapat melakukan verifikasi tiket. Perintah verifikasi tersebut dikirimkan ke server dan kemudian server akan mengganti status tiket dari yang asalnya Aktif menjadi Terverifikasi sehingga tiket tersebut kini tidak lagi valid.

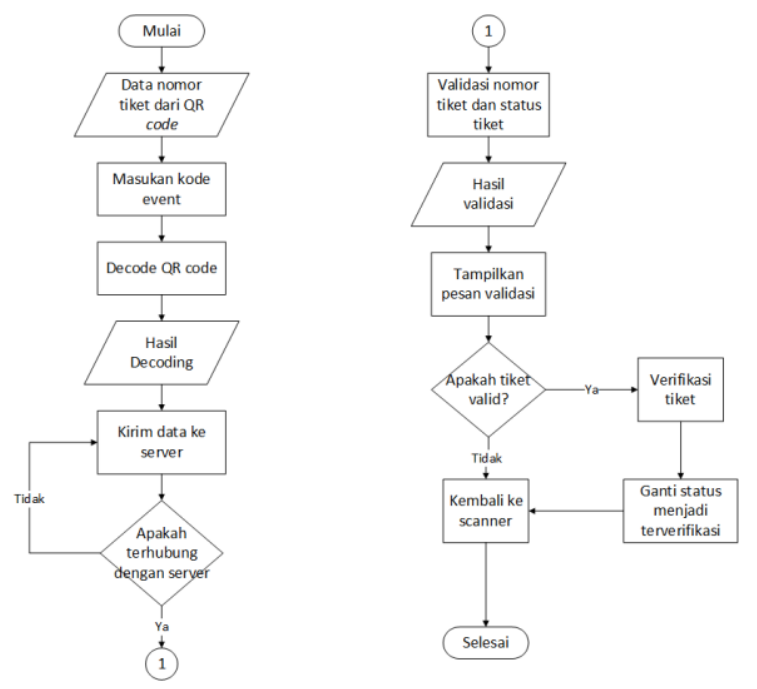

Gambar 12. Diagram Alur Proses Pembacaan Tiket

\subsection{Analisis Kebutuhan Fungsional \\ 2.3.1 Use Case Diagram}




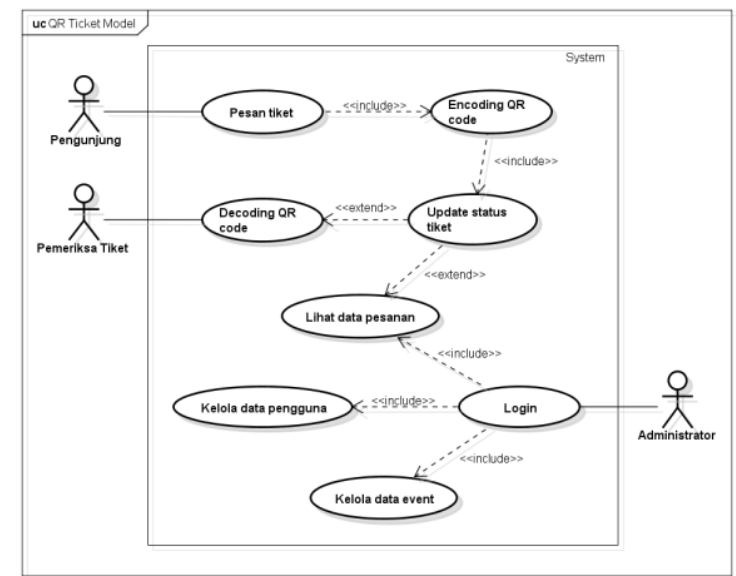

Gambar 15. Use Case Diagram

\subsubsection{Class Diagram}

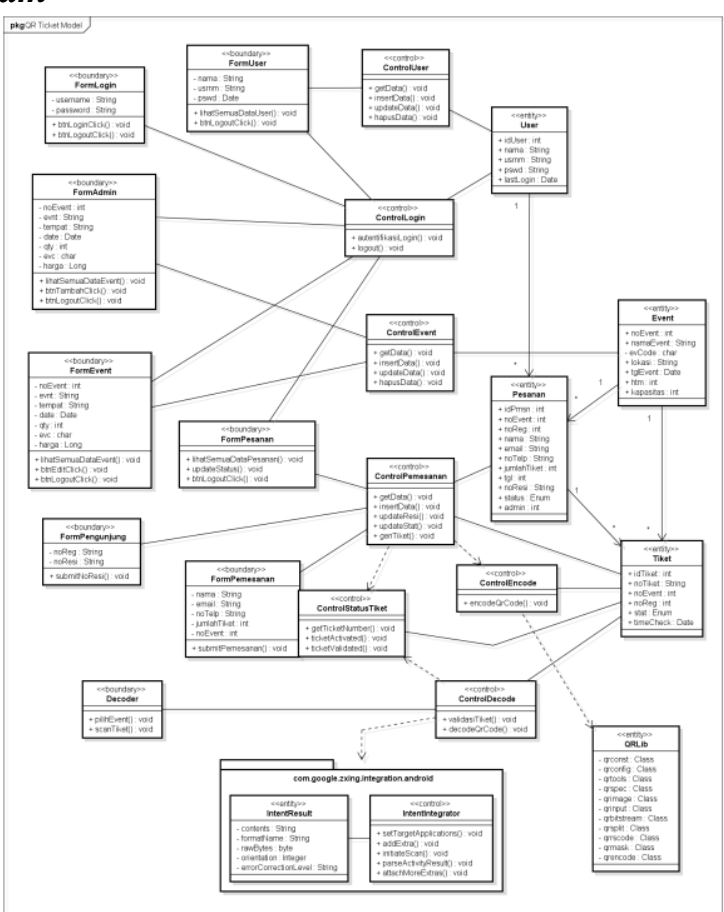

Gambar 16. Class Diagram

\subsection{Implementasi}

Implementasi dari sistem dibagi menjadi server berbasis website dan decoder berbasis mobile. 


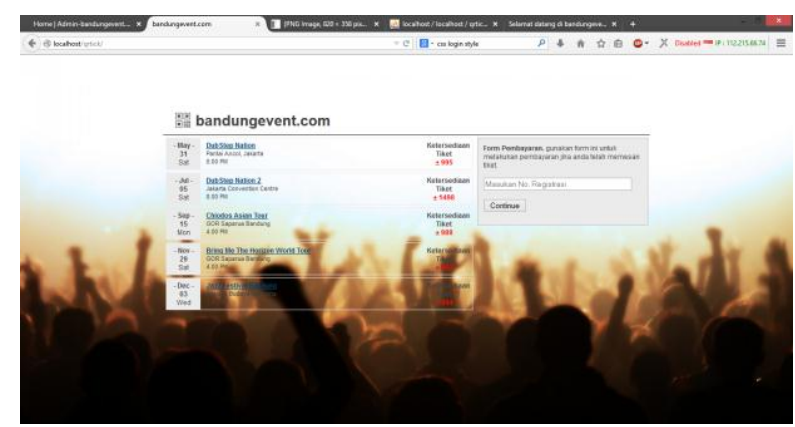

Gambar 17. Implementasi Server

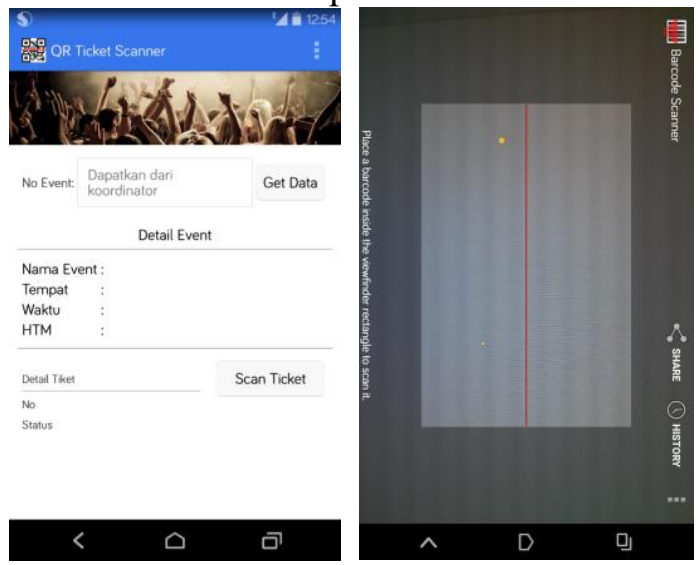

Gambar 18. Implementasi Decoder

\subsection{Hasil Pengujian}

Pengujian dilakukan 2 media QR code berbeda dengan beberapa konsdisi, dari kondisi lingkungan dan tingkat kerusakan untuk membandingkan kemampuan pembacaan QR code dari 4 tingkat koreksi kesalahan yang berbeda.

Tabel 8. Hasil Pengujian QR Code Utuh

\begin{tabular}{|c|c|c|c|}
\hline \multicolumn{3}{|c|}{ QR Code Ditampilkan pada Layar Ponsel } \\
\hline \multirow{4}{*}{$\begin{array}{c}\text { Kondisi } \\
\text { Pengujian }\end{array}$} & $\begin{array}{c}\text { Tumlah } \\
\text { Tingkat } \\
\text { Koreksi } \\
\text { Kesalahan } \\
\text { Code } \\
\text { Terbaca } \\
/ \\
\text { Jumlah } \\
\text { Sampel }\end{array}$ & $\begin{array}{c}\text { Persentase } \\
\text { QR Code } \\
\text { Terbaca }\end{array}$ \\
\hline \multirow{3}{*}{$\begin{array}{c}\text { Cukup } \\
\text { Cahaya }\end{array}$} & Low & $20 / 20$ & $100 \%$ \\
\cline { 2 - 4 } & Medium & $20 / 20$ & $100 \%$ \\
\cline { 2 - 4 } & Quartile & $20 / 20$ & $100 \%$ \\
\cline { 2 - 4 } Kurang \\
Cahaya & High & $20 / 20$ & $100 \%$ \\
\cline { 2 - 4 } & Ledium & $20 / 20$ & $100 \%$ \\
\cline { 2 - 4 } & Quartile & $20 / 20$ & $100 \%$ \\
\hline
\end{tabular}




\begin{tabular}{|c|c|c|c|}
\hline & High & $20 / 20$ & $100 \%$ \\
\hline \multicolumn{2}{|c|}{ Rata-Rata } & $160 / 160$ & $100 \%$ \\
\hline \multicolumn{4}{|c|}{ QR Code Dicetak pada Kertas } \\
\hline $\begin{array}{c}\text { Kondisi } \\
\text { Pengujian }\end{array}$ & $\begin{array}{c}\text { Tingkat } \\
\text { Koreksi } \\
\text { Kesalahan }\end{array}$ & $\begin{array}{c}\text { Jumlah } \\
\text { QR } \\
\text { Code } \\
\text { Terbaca } \\
\text { / } \\
\text { Jumlah } \\
\text { Sampel } \\
\end{array}$ & $\begin{array}{l}\text { Persentase } \\
\text { QR Code } \\
\text { Terbaca }\end{array}$ \\
\hline \multirow{4}{*}{$\begin{array}{l}\text { Cukup } \\
\text { Cahaya }\end{array}$} & Low & $20 / 20$ & $100 \%$ \\
\hline & Medium & $20 / 20$ & $100 \%$ \\
\hline & Quartile & $20 / 20$ & $100 \%$ \\
\hline & High & $20 / 20$ & $100 \%$ \\
\hline \multirow{4}{*}{$\begin{array}{l}\text { Kurang } \\
\text { Cahaya }\end{array}$} & Low & $20 / 20$ & $100 \%$ \\
\hline & Medium & $20 / 20$ & $100 \%$ \\
\hline & Quartile & $20 / 20$ & $100 \%$ \\
\hline & High & $20 / 20$ & $100 \%$ \\
\hline \multicolumn{2}{|c|}{ Rata-Rata } & $160 / 160$ & $100 \%$ \\
\hline
\end{tabular}

Tabel 9. Hasil Pengujian QR Code Tidak Utuh

\begin{tabular}{|c|c|c|c|}
\hline \multicolumn{4}{|c|}{ QR Code Dicetak pada Kertas } \\
\hline $\begin{array}{l}\text { Kondisi } \\
\text { Pengujian }\end{array}$ & $\begin{array}{c}\text { Tingkat } \\
\text { Koreksi } \\
\text { Kesalahan }\end{array}$ & $\begin{array}{c}\text { Tingkat } \\
\text { Kerusakan } \\
\text { QR Code }\end{array}$ & $\begin{array}{c}\text { Jumlah } \\
\text { QR } \\
\text { Code } \\
\text { Terbaca } \\
\text { / } \\
\text { Jumlah } \\
\text { Sampel } \\
\end{array}$ \\
\hline \multirow{8}{*}{$\begin{array}{l}\text { Cukup } \\
\text { Cahaya }\end{array}$} & \multirow{2}{*}{ Low } & $5 \%$ & $5 / 5$ \\
\hline & & $10 \%$ & $0 / 5$ \\
\hline & \multirow{2}{*}{ Medium } & $5 \%$ & $5 / 5$ \\
\hline & & $10 \%$ & $1 / 5$ \\
\hline & \multirow{2}{*}{ Quartile } & $5 \%$ & $5 / 5$ \\
\hline & & $10 \%$ & $2 / 5$ \\
\hline & \multirow{2}{*}{ High } & $5 \%$ & $5 / 5$ \\
\hline & & $10 \%$ & $5 / 5$ \\
\hline \multirow{6}{*}{$\begin{array}{l}\text { Kurang } \\
\text { Cahaya }\end{array}$} & \multirow{2}{*}{ Low } & $5 \%$ & $5 / 5$ \\
\hline & & $10 \%$ & $0 / 5$ \\
\hline & \multirow{2}{*}{ Medium } & $5 \%$ & $5 / 5$ \\
\hline & & $10 \%$ & $1 / 5$ \\
\hline & \multirow{2}{*}{ Quartile } & $5 \%$ & $5 / 5$ \\
\hline & & $10 \%$ & $2 / 5$ \\
\hline
\end{tabular}




\begin{tabular}{|c|c|c|c|}
\hline \multirow{2}{*}{ High } & $5 \%$ & $5 / 5$ \\
\cline { 2 - 3 } & $10 \%$ & $5 / 5$ \\
\hline \multicolumn{2}{|c|}{$\begin{array}{l}\text { Rata-Rata (Total QR code } \\
\text { terbaca / Jumlah sampel ) }\end{array}$} & $\mathbf{5 6 / 8 0}$ \\
\hline
\end{tabular}

\section{PENUTUP}

\subsection{Kesimpulan}

Setelah melakukan analisis, perancangan, implementasi dan pengujian, maka dapat diperoleh kesimpulan sebagai berikut.

1. Verifikasi tiket yang diperbaharui dengan sistem komputerisasi dapat meningkatkan kualitas dari verifikasi tiket. Berdasarkan hasil pengujian, hanya tiket dengan kode event yang sesuai dengan yang sedang berlangsung dan memiliki status Aktif yang dapat diverifikasi oleh sistem.

2. Berhasil dibangun suatu sistem untuk menggantikan bentuk fisik tiket menjadi QR code untuk memudahkan proses distribusi tiket secara presale dan membuat tiket tersebut lebih akurat dalam proses verifikasi.

3. Tingkat koreksi kesalahan Reed-Solomon error correction code yang ada pada $\mathrm{QR}$ code ternyata memang mempengaruhi kemapuan baca dari QR code. Akan tetepi pengaruh dari tingkat koreksi kesalahan ini sangat terasa pada tingkat koreksi kesalahan High dan ketika ada tiket QR code yang mengalami kerusakan dengan toleransi tingkat kerusakan fisik sekitar $10 \%$.

\subsection{Saran}

Agar pemanfaatan QR code sebagai tiket masuk event ini semakin baik untuk kedepannya, maka ada beberapa saran yang perlu dilakukan dalam penelitian berikutnya, diantaranya:

1. Ketika QR code akan digunakan pada lingkungan yang rawan kerusakan akibat lingkungan atau media QR code itu sendiri, sebaiknya gunakan tingkat koreksi kesalahan High karena dapat mengembalikan codewords hingga 30\%.

2. Sistem yang dibangun, khususnya encoder dibatasi pada tiket yang dijual presale dan sistem ini tidak mengelola pembayaran. Pembayaran disini hanya sebagai simulasi untuk menentukan status tiket. Jadi, untuk kedepannya disarankan agar menambahkan fungsionalitas pembayaran sehingga pengunjung akan lebih dimudahkan dalam proses pembelian tiket.

3. Jika melihat batasan akan tiket presale, disarankan untuk menambahkan fungsional mencetak tiket bagi pihak Event Organizer sehingga tiket yang dijual on-the-spot pun sudah dalam bentuk QR code walaupun tercetak dalam kertas. Dengan itu, sistem ini pun akan memiliki fungsionalitas yang lebih lengkap sehingga akan lebih handal untuk menggantikan sistem tiket konvensional. 


\section{DAFTAR PUSTAKA}

[1] Sankara, A. 2012. QR Codes and Security Solutions. International Journal of Computer Science and Telecommunications, Vol. 3, Issue 7.

[2] Septirasyahyani dan Usman, Koredianto. 2012. Desain dan Implementasi Qr Code Berbasiskan Pengolahan Citra Digital untuk Sistem Parkir di IT Telkom. Jurnal Informatika. Retrived from: http://kru.blog.ittelkom.ac.id/blog/files/downloads/2012/12/JURNAL SEPTI KRU L DN_U_SNAKOM2012.pdf

[3] Zhang, Mu dan Yao, Dan. 2012. The Application and Design of QR Code in Scenic Spot's eTicketing System. International Journal of Science and Technology, vol. 2, ISSN 2224-3577.

[4] Swetake. "How to create QRcode" (online). http://www.swetake.com/qrcode/qr1_en.html (30 Apr 2014)

[5] Thonky. "Error Correction Coding” (online). http://www.thonky.com/qr-codetutorial/error-correction-coding (4 Jun 2014) 